\title{
REVISÃO
}

\section{UTENSÍLIOS PARA ALIMENTOS E IMPLICAÇÕES NUTRICIONAIS}

\section{FOOD UTENSILS AND NUTRITIONAL IMPLICATIONS}

Késia Diego QUINTAES'

RESUMO

\begin{abstract}
Há grande variedade de materiais empregados na confecção de utensílios para os alimentos: barro, ferro, vidro, cerâmica, inox, pedra, alumínio e outros. Cerca de $43 \%$ de panelas vendidas atualmente nos Estados Unidos são de aço inoxidável. Outra parcela da população utiliza utensílios de alumínio. Este artigo visa especular a contribuição nutricional de utensílios usados na preparação de alimentos e feitos de três diferentes materiais (alumínio, ferro e aço inoxidável), através de revisão de literatura científica.
\end{abstract}

Termos de indexação: utensílios de alimentação e culinária, ferro, alumínio, inox, níquel, cromo.

\begin{abstract}
Many materials are used to make food utensils: clay, iron, glass, pottery stainless steel, stone, aluminum, etc. Stainless steel utensils account for $43 \%$ of cookware sold in the USA. Another part of the population uses aluminum utensils. This article aims at speculating on the nutritional contribution of utensils used for food preparation and made from three different materials (aluminum, iron and stainless steel), through a review of scientific literature.
\end{abstract}

Index terms: cooking and eating utensils, iron, aluminum, stainless steel, nickel, chromium.

\section{INTRODUÇÃO}

É impraticável pensar na Nutrição isolada dos utensílios para alimentos, uma vez que estes são indispensáveis no preparo e na elaboração culinária. Diversos são os materiais utilizados pelo homem, tanto artesanal como industrialmente, na confecção dos utensílios: ferro, alumínio, inox, cerâmica, pedra, vidro, barro e outros. Entretanto, pouco se fala sobre o efeito, quer positivo ou negativo que os utensílios podem exercer nos alimentos.

O saber popular há muito indicou que a utilização de panelas de ferro na cocção de alimentos é um meio preventivo e mesmo auxiliar no tratamento da anemia ferropriva, apontando diretamente para um possível efeito migratório do ferro do utensílio para o alimento preparado. Por outro lado, podemos imaginar que o contrário também é verdadeiro: elementos indesejáveis contidos em determinados utensílios, como o alumínio e o níquel entre outros, podem migrar para os alimentos durante o processo de cocção. Assim sendo, o objetivo deste artigo é, mediante as mais recentes informações científicas disponíveis, descrever as implicações nutricionais de utensílios de três diferentes materiais (alumínio, ferro e aço inoxidável).

\footnotetext{
${ }^{(1)}$ Departamento de Planejamento Alimentar e Nutrição, Faculdade de Engenharia de Alimentos, Universidade Estadual de Campinas. 13083-970, Campinas, SP, Brasil. E-mail: kesia@fea.unicamp.br
} 


\section{UTENSÍLIOS DE ALUMÍNIO}

O alumínio é o terceiro elemento mais abundante da crosta terrestre, sendo precedido apenas pelo silício e pelo oxigênio (Rochow, 1987). No homem, sua toxidade está reconhecidamente associada à várias complicações clínicas, destacando-se nestas, disfunções neurológicas como o mal de Alzheimer (Luckey \& Venugopal, 1977; Greger et al., 1985; Alfrey, 1986; Edwardson et al, 1986; Fimreite et al., 1997; Roberts et al., 1998). O alumínio está ainda envolvido com a mobilização do fosfato ósseo (Oniwanwa et al., 1997). No homem, a concentração plasmática usual de alumínio é de aproximadamente $5 \mu \mathrm{g} / \mathrm{l}$, sendo seu maior carreador a transferrina (Alfrey, 1986).

As diversas fontes de alumínio, para o homem incluem, o ar, desodorantes anti-transpirantes, cosméticos, aditivos alimentares, chá, a própria água consumida, sendo que esta última teve, nos últimos anos, um acréscimo no conteúdo de alumínio em decorrência da chuva ácida. Medicamentos como antiácidos, contendo hidróxido de alumínio, podem também contribuir para um aumento na ingestão de alumínio pelos usuários destas drogas (Liukkonen-Lilja \& Pieppone, 1992; Aikoh \& Nishio, 1996; Fimreite et al., 1997).

Por outro lado, pacientes com insuficiência renal crônica estão constantemente expostos a altos níveis de alumínio através da água utilizada na diálise e, muitos destes apresentando efeitos decorrentes desta exposição: anemia, osteomalácia e encefalopatia (Alfrey, 1986; Edwardson et al., 1986; Fimreite et al., 1997; Roberts et al., 1998).

As concentrações de alumínio nos alimentos é tipicamente baixa, usualmente inferior a $5 \mathrm{mg} / \mathrm{kg}$, e sua ingestão diária varia de 3 a $36 \mathrm{mg}$, onde o valor mais alto foi constatado nos primeiros estudos feitos sobre o assunto. Apesar disto, a indústria de alimentos, mediante a utilização de determinados aditivos alimentares, pode aumentar claramente a quantidade de alumínio nos alimentos processados (Alfrey, 1986; Liukkonen-Lilja \& Pieppone, 1992; Aikoh \& Nishio, 1996).

Assim sendo, o conteúdo de alumínio nos alimentos apesar de pequeno torna-se suscetível a variações. Sua concentração mais elevada é encontrada em conservas de picles e de queijos, além do fermento. Portanto, dependendo dos hábitos alimentares individuais, a ingestão de alumínio pode ser mais elevada do que a média estimada. Outra fonte de ingestão deste que geralmente é desconsiderada é a água. Um levantamento norte-americano mostrou que a água consumida pela população contém em média de 2 a 4 mg/l (Alfrey, 1986). Entretanto, uma fonte trivial (quando comparada com as demais) na ingestão de alumínio tem recebido pouca atenção: os utensílios culinários. Há mais de 50 anos é conhecido que os utensílios de alumínio são vulneráveis à degradação, principalmente por alimentos de $\mathrm{pH}$ ácido
(Alfrey, 1986; Baxter, et al., 1988; Fimreite et al., 1997).

Os estudos indicam que vários são os fatores que influenciam a migração do alumínio do utensílio: a qualidade da liga de alumínio utilizada pela indústria, o tempo de uso do utensílio, o tempo da duração da cocção dos alimentos, o pH do alimento, a presença de sal ou açúcar, entre outros (Pennington, 1987; Liukkonen-Lilja \& Pieppone, 1992).

Lione (1984) demonstrou que utensílios de alumínio, utilizados na preparação de molho de tomate, podem contribuir com um acréscimo de $4 \mathrm{mg}$ em cada porção servida. Lione et al. (1984), reforçaram seus achados em outra preparação usualmente consumida no mundo inteiro: o café. Este, quando preparado em utensílio de alumínio apresentava um considerável acréscimo do metal.

Fimreite et al. (1997) reforçaram a ocorrência da contaminação dos alimentos com alumínio migrante de utensílios culinários, ao avaliarem o nível deste metal contido em alimentos ácidos preparados em panelas de alumínio. Os resultados obtidos mostraram que os utensílios de alumínio, freqüentemente utilizados pela população, são indubitavelmente fontes deste metal na dieta.

Em relação ao tempo de uso da panela foi observado através de testes com água potável que, utensílios novos possuem uma migração maior de alumínio no ponto de ebulição comparada a de utensílios usados. Entretanto, quando o tempo se prolonga para 15 ou 30 minutos de fervura, o comportamento de ambos os utensílios (novos e usados) é similar no que diz respeito à dissolução do alumínio (Liukkonen-Lilja \& Pieppone, 1992). Neste sentido, Greger et al. (1985) verificaram que preparações ácidas como molho de tomate que levam mais que 15 minutos de cozimento, tendem a acumular mais alumínio do que outras preparações. Em termos práticos estes autores concluíram que a quantidade do alumínio adicionado ao alimento durante a cocção em utensílios deste material chega a ser de até $0,7 \mathrm{mg} / 100 \mathrm{~g}$ de alimento.

Recentemente, um estudo italiano desenvolvido por Gramiccioni et al. (1996), no qual foi avaliada a migração de alumínio de utensílios para preparações culinárias elaboradas nestes, concluíram que a quantidade migrante é relativamente pequena. Segundo este estudo, essa ingestão mesmo quando todos os alimentos são preparados e estocados em recipientes de alumínio, é de aproximadamente $6 \mathrm{mg} / \mathrm{dia}$, ou seja, inferior ao valor de $7 \mathrm{mg} / \mathrm{kg}$ (equivalente a $60 \mathrm{mg} /$ dia para um homem adulto) estabelecido como tolerável pelo Joint FAO/ WHO Expert Committee on Food Additives (World..., 1989).

Aikoh \& Nishio (1996) documentaram um aumento expressivo na quantidade de alumínio presente em bebidas enlatadas e estocadas em recipientes de alumínio, como 
refrigerantes, cervejas e chá. Assim, a questão permanece controversa, pois neste estudo os autores concluíram que as pessoas que utilizam freqüentemente bebidas enlatadas podem estar consumindo quantidades de alumínio consideravelmente elevadas.

Com relação ao tipo do utensílio, foi demonstrado que formas de bolo não acarretam aumento no consumo diário desse metal (Liukkonen-Lilja \& Pieppone, 1992). O mesmo não se pode dizer quando o utensílio analisado é a panela de pressão, nesta há um acréscimo muito significante na quantidade final de alumínio. Já utensílios como frigideiras e panelas comuns, apresentam semelhança no que diz respeito à degradação, neste caso o fator diferencial mais expressivo é o próprio alimento utilizado na preparação do que o tipo do utensílio propriamente dito (Greger et al., 1985).

Outro fator que merece destaque é o da composição da liga de alumínio utilizada pela indústria. Baxter et al. (1988) descreveram dois tipos clássicos de composição desta liga: 1) alumínio/silício/ferro e, 2) alumínio/silício/ manganês. Estes autores referiram que utensílios feitos com liga contendo manganês possuem maior degradação de alumínio quando comparados com a liga contendo ferro. Este fator também é referido por outros autores como sendo de relevância para os resultados obtidos (Greger et al., 1985; Pennington, 1987; Liukkonen-Lilja \& Pieppone, 1992).

Liukkonen-Lilja \& Pieppone (1992) demonstraram que o teor de sal ou açúcar na preparação também afeta a dissolução do alumínio do utensílio. Estes autores verificaram em seus experimentos que esta influência já é sentida mesmo com os sais naturalmente presentes na água potável. A adição de dois diferentes sais $\left(\mathrm{NaHCO}_{3}\right.$ e $\left(\mathrm{aCl}_{2}\right.$ ) a água deionizada causou similarmente um aumento na migração de alumínio do utensílio. Na conclusão, os autores desaconselharam a utilização de recipientes de alumínio para armazenamento de preparações, principalmente se estas possuírem um alto conteúdo de sal.

Os efeitos resultantes da ingestão de alumínio dependem obviamente da absorção, esta, por sua vez, depende da forma química do metal, sendo vários os fatores responsáveis pela biodisponibilidade do alumínio (Fimreite et al., 1997; Roberts et al., 1998). Estudos mostram que cerca de 75 a 95\% do alumínio ingerido é eliminado na urina e nas fezes, o restante é absorvido e depositado em vários órgãos como os ossos e pulmões (Alfrey, 1986).

Praticamente todos os estudos sobre migração de alumínio dos utensílios para os alimentos deixam claro que estes fornecem uma importante contribuição na quantidade do metal consumida pelo homem, mas a ligação entre esta fonte e os efeitos biológicos possíveis ainda é confusa. Em todo caso, recomendável evitar estes utensílios no preparo, na cocção e no armazenamento dos alimentos.

\section{UTENSÍLIOS DE FERRO}

O ferro é um nutriente indispensável ao homem, os sinais e sintomas da sua deficiência são logo notados: fadiga, cefaléia, palpitações, entre outros. Se esta deficiência não for corrigida rapidamente pode trazer seqüelas duradouras e até letais, por este motivo a anemia é considerada como um dos maiores desafios à Saúde Pública a ser vencido. Considerando que a deficiência de ferro está disseminada mundialmente em todas as classes sociais, faixas etárias e em ambos os sexos, muito se tem investido em pesquisas que proponham soluções para sua erradicação (Morris, 1986; Yip \& Dallman, 1996).

Uma vez que o problema mundial da deficiência de ferro tem como causa principal a ingestão inadequada e a baixa biodisponibilidade encontrada no ferro dos alimentos, os utensílios culinários de ferro podem ser considerados como uma solução alternativa para a prevenção e tratamento da anemia, segundo os vários estudos publicados sobre migração deste mineral dos utensílios para os alimentos (Brittin \& Nossaman, 1986; Mistry et al., 1988; Cheng \& Brittin, 1991; Kollipara \& Brittin, 1996; Gibson et al., 1997; Kakade \& Agte, 1997).

Muitas pesquisas demonstraram que o $\mathrm{pH}$ do alimento tem uma influência direta sobre a quantidade de ferro acrescentada a este durante a cocção. Alimentos ácidos como molho de tomate, apresentam um acréscimo maior de ferro do que alimentos menos ácidos. Também ficou documentado em vários estudos que, tanto o teor de água como o tempo de cocção dos alimentos exercem uma influência direta no acréscimo de ferro ao alimento. Entretanto o pH e o tempo de cocção são fatores de maior peso quando comparados com a umidade da preparação (Brittin \& Nossaman, 1986; Zhou \& Brittin, 1994; Kollipara \& Brittin, 1996).

Cheng \& Brittin (1991) executaram um experimento onde foram feitas 50 cocções repetidas em utensílios de ferro com a finalidade de verificar o comportamento do utensílio no decorrer do tempo de uso. A conclusão dos autores foi que as panelas de ferro, além de possuírem uma vida útil bastante longa, permanecem liberando o nutriente para os alimentos preparados de forma similar a uma panela de ferro nova. Apenas nas três primeiras vezes de uso a quantidade de ferro liberada pela panela nova é inferior a de uma já bastante usada.

Kakade \& Agte (1997) utilizaram em seu experimento diversos alimentos e compararam a cocção destes em utensílios de ferro com a cocção em utensílios de ferro antiaderentes. Os autores concluíram que a quantidade de ferro migrante dos utensílios de ferro é bastante superior à dos utensílios de ferro antiaderentes. Seus resultados indicaram a ocorrência de um aumento de 46 a 51\% no ferro biodisponível do alimento, quando utensílios de ferro são usados na elaboração culinária.

Em outro estudo Mistry et al. (1988) determinaram por método in vitro que a disponibilidade do ferro de 
alimentos preparados em utensílios de ferro e em utensílios de vidro é similar, indicando que o ferro adicionado ao alimento pela cocção em panelas de ferro é tão disponível quando o ferro não-heme natural do alimento.

Kollipara \& Brittin (1996) pesquisando o acréscimo no conteúdo de ferro na culinária indiana preparadas em utensílios de ferro obtiveram como resultado um aumento médio de $374 \%$ por mês na ingestão de ferro por meio dos alimentos preparados em utensílios de ferro. Um outro estudo envolvendo comidas chinesas elaboradas em utensílio de aço, mostrou também um acréscimo na quantidade de ferro contida nos alimentos preparados no utensílio em questão (Zhou \& Brittin, 1994).

Mas mesmo considerando que o ferro migrante do utensílio possui boa disponibilidade para o organismo (Brittin \& Nossaman, 1986; Mistry et al., 1988; Kollipara \& Brittin, 1996) e que, uma parcela importante da população ainda utiliza panelas de ferro, tal fato é ignorado nos inquéritos dietéticos. Até hoje somente considera-se no inquérito dietético sobre ferro, fatores como o ácido ascórbico e a carne, por auxiliarem e aumentarem sua absorção, conforme demonstrado pioneiramente por Monsen et al. (1978). Entretanto, a utilização de utensílios de ferro na cocção dos alimentos aumenta significantemente a quantidade de ferro consumida.

Gibson et al. (1997) propuseram pequenas alterações em dietas vegetarianas de adolescentes canadenses do sexo feminino, com a finalidade de aumentar a quantidade de ferro não-heme e de zinco biodisponível, uma vez que este tipo de alimentação usualmente é pobre nestes nutrientes. No que diz respeito ao ferro, a utilização de panela de ferro no preparo da dieta foi uma das alterações efetuadas que teve impacto positivo nos resultados. Os autores relataram um aumento potencial tanto no conteúdo como na biodisponibilidade do ferro não-heme, ultrapassando inclusive os valores propostos pela Recommend Dietary Allowances (RDA) (National Research..., 1989) para a faixa etária. Isto tudo foi obtido sem, entretanto, acarretar mudanças no tipo e na quantidade de alimentos consumida pelas adolescentes vegetarianas canadenses.

\section{UTENSÍLIOS DE AÇO INOXIDÁVEL}

A liga do aço inoxidável (inox) é uma combinação do ferro com outros dois metais: cromo e níquel. Sendo a proporção destes metais nos utensílios bastante variável: de 50 a $88 \%$ para o ferro, 11 a $30 \%$ para o cromo e de zero a $31 \%$ para o níquel. Entretanto, vários outros elementos como manganês e cobre, podem estar presentes em pequenas quantidades (Kuligowski \& Halperin, 1992; Flint \& Packirisamy, 1997; Park \& Brittin, 1997).

O mercado dos utensílios de inox está em expansão e atualmente responde por cerca de $43 \%$ das panelas que são vendidas nos Estados Unidos (Park \& Brittin, 1997). A composição da liga de inox mais encontrada é de 70 a $73 \%$ de ferro, 18 a 19\% de cromo e 8 a 9\% de níquel (Kuligowski \& Halperin, 1992; Flint \& Packirisamy, 1997).

O níquel é um dos metais mais tóxicos da tabela periódica, estando relacionado a numerosos problemas de saúde, notavelmente nas dermatites de contato (Kuligowski \& Halperin, 1992; Nielsen, 1996; Agarwal, et al., 1997).

O níquel ingerido pelo homem encontra-se distribuído entre os vários grupos de alimentos. As maiores concentrações são encontradas em alimentos enlatados, açúcares e conservantes, pães e cereais, sugerindo uma contribuição dos equipamentos de processamento dos alimentos, principalmente no caso dos enlatados e da gordura vegetal hidrogenada (Smart \& Sherlock, 1987). Nos alimentos in natura as maiores concentrações de níquel são encontradas nas nozes, sementes de leguminosas, mariscos, cacau e derivados. Grãos, carnes curadas e vegetais são intermediários, enquanto que alimentos de origem animal como peixes, leite e ovos geralmente apresentam baixo conteúdo de níquel.

A ingestão média de níquel estimada é de 150-700 $\mu \mathrm{g} /$ dia, esta variação é dependente da quantidade de alimentos de origem animal (baixo níquel) e de origem vegetal (alto níquel) consumida. As manifestações de uma dieta com alto conteúdo de níquel pode afetar os níveis de outros nutrientes e, mais do que isto, a deficiência de alguns nutrientes (ferro, cobre, zinco, ácido ascórbico, entre outros) pode ser agravada por um alto nível de níquel na dieta.

A maior parte do níquel ingerido é excretada nas fezes, entretanto uma alta porcentagem deste será absorvida no caso de deficiência de ferro. No sangue o níquel é transportado principalmente ligado à albumina sérica. Ainda não está bem esclarecida a função do níquel em humanos, entretanto supõe-se que esteja ligado a metaloenzimas específicas como componente estrutural destas, além de co-fator bioligante que facilita a absorção intestinal do ferro férrico (Nielsen, 1986).

A contribuição de níquel na ingestão diária devida a migração deste durante a cocção dos alimentos em utensílios de inox é pequena; é estimado um acréscimo médio de 0,01 a 0,21 mg/l (Kuligowski \& Halperin, 1992; Kumar et al., 1994). Mesmo assim, é recomendado que pessoas sensíveis ao níquel não utilizem utensílios de inox na cocção e preparo dos alimentos pois, a migração deste do utensílio para o alimento, apesar de pequena, não é desprezível, ainda mais se considerarmos o efeito acumulativo do consumo diário de alimentos preparados em utensílios de aço inoxidável.

Vários autores já documentaram que os utensílios de inox são fonte de dois nutrientes essenciais a população: o cromo e o ferro (Kuligowski \& Halperin, 1992; Kumar et al., 1994; Park \& Brittin, 1997). A intolerância a glicose, seguida de anormalidades no metabolismo glicídico e 
lipídico, além de desordens nervosas são sintomas da deficiência de cromo.

O requerimento nutricional do cromo para adultos, segundo a RDA, é de 50-200 $\mu \mathrm{g} /$ dia (National Research..., 1989). Este valor não é facilmente alcançado uma vez que atualmente a participação de produtos industrializados e refinados na alimentação é bastante grande, o processamento promove perdas consideráveis na quantidade de cromo. Estudos indicam que a ingestão diária média de cromo pela população é inferior a $60 \mu \mathrm{g}$ (Anderson, 1986). Entretanto, nestes levantamentos foi considerado apenas o cromo contido nos alimentos, não incluindo o cromo migrante dos utensílios de inox.

Kuligowski \& Halperin (1992) estudaram a migração de ferro, níquel e cromo dos utensílios de inox para o ácido acético a 5\%, procurando simular, desta forma, a condição geralmente corrosiva dos alimentos. Neste trabalho os autores demonstraram que os utensílios de inox são fonte considerável de cromo na alimentação, contribuindo com um créscimo de 0,01 a 0,31 mg/l no alimento preparado. Os resultados apresentados ainda indicaram que, o aço inoxidável também é uma fonte expressiva de ferro, apesar da quantidade ser inferior a que ocorre em utensílios de ferro fundido.

Como anteriormente já discutimos sobre a carência e a importância do ferro na alimentação mundial, aqui apenas falaremos dos achados científicos em relação a contribuição nutricional deste nutriente fornecida pelo uso de utensílios de aço inoxidável na culinária.

A cocção de alimentos em utensílios de inox aumenta o conteúdo de ferro nos alimentos, principalmente quando é feito o cálculo dietético diário, uma vez que, o ferro derivado do utensílio possui biodisponibilidade similar a do ferro não-heme encontrado naturalmente nos alimentos (Martinez \& Vannucchi, 1986; Mistry et al., 1988, Kuligowski \& Halperin, 1992; Park \& Brittin, 1997).

Park \& Brittin, (1997) verificaram que a quantidade de ferro contida em 10 alimentos diferentes preparados em utensílios de inox é significantemente maior do que quando estes são preparados em utensílios de vidro. Os valores obtidos demonstraram que em cada $100 \mathrm{~g}$ de porção servida havia um acréscimo de 1,02 mg de ferro. $O$ experimento foi realizado em triplicata com a finalidade de verificar possíveis diferenças na migração entre as panelas. Neste sentido, os resultados indicaram que o acréscimo no conteúdo de ferro não diferiu significativamente entre as panelas de aço inoxidável utilizadas.

\section{COMENTÁRIOS FINAIS}

Apesar de os utensílios de alumínio serem bastante difundidos no mercado, este metal está associado a doenças neurodegenerativas como o mal de Alzheimer. Considerando que os utensílios de alumínio são indiscutivelmente fonte deste elemento, o uso diário destes aumenta consideravelmente a ingestão de alumínio. Portanto é aconselhável que seu uso na culinária seja evitado.

Os estudos apontam diretamente para o saber popular: a utilização diária de panelas de ferro no preparo e cocção dos alimentos contribui para o tratamento e prevenção da anemia ferropriva. Estes utensílios são bastante duráveis e permanecem sempre liberando o ferro para os alimentos, sendo que quanto mais ácido for o $\mathrm{pH}$ do alimento maior será a migração de ferro do utensílio.

Os utensílios de inox contribuem na ingestão de ferro e de cromo, ambos nutrientes essenciais. Entretanto estes utensílios também são fonte de níquel, tóxico ao homem. Mesmo sendo a migração de níquel em baixa quantidade, não é desprezível, ainda mais se houver um consumo diário de alimentos preparados em utensílios de inox. É recomendável que pessoas sensíveis ao níquel evitem a utilização destes utensílios. Como não existe uma exigência na composição da liga de inox, o níquel pode estar em quantidades superiores ou inferiores a dos estudos aqui apresentados. Assim, seria interessante que a quantidade de níquel utilizada industrialmente na liga de inox fosse padronizada no menor nível possível.

Outra constatação importante a ser feita é que, apesar de ser expressiva a quantidade de ferro migrante tanto dos utensílios de ferro com de inox, este valor não é levado em consideração nos recordatórios alimentares e nos inquéritos dietéticos populacionais, mesmo estando comprovada a boa biodisponibilidade do metal.

\section{REFERÊNCIAS BIBLIOGRÁFICAS}

AGARWAL, P., SRIVASTAVA, S., SRIVASTAVA, M.M., PRAKASH, S., RAMANAMURTHY, M., SHIRIVASTAV, R., DASS, S. Studies on leaching of $\mathrm{Cr}$ and $\mathrm{Ni}$ from stainless steel utensils in certain acids and in some Indian drinks. Science of the Total Environment, Amsterdam, v.199, n.3, p.271-275, 1997.

AIKOH, H., NISHIO, M.R. Aluminium content of varius canned an bottled beverages. Bulletin of Environmental Contamination and Toxicology, New York, v.56, n.1, p.1-7, 1996.

ALFREY, A.C. Aluminum. In: MERTZ, W. (Ed.). Trace elements in human and animal nutrition. 5ed. San Diego : Academic Press, 1986. v.2: p.399-413.

ANDERSON, R.A. Chromium. In: MERTZ, W. (Ed.). Trace elements in human and animal nutrition. 5.ed. San Diego : Academic Press, 1986. v.1: p.225-244.

BAXTER, M., BURRELL, J.A., MASSEY, R.C. The effects of fluoride on the leaching of aluminium saucepans during cooking. Food Additives and Contaminants, London, v.5, n.4, p.651-656, 1988.

BRITTIN, H.C., NOSSAMAN, C.E. Iron content of food cooked in iron utensils. Journal of the American Dietetic Association, Chicago, v.86, n.7, p.897-901, 1986. 
CHENG, Y.J., BRITTIN, H.C. Iron in food: effect of continued use of iron cookware. Journal of Food Science, Chicago, v.56, n.2, p.584-585, 1991.

EDWARDSON, J.A., KLINOWSKI, J., OAKLEY, A.E., PERRY, R.H., CANDY, J.M. Aluminosilicates and the ageing brain: implications for the patogenesis of Alzheimer's disease. In: EVERED, D., O'CONNOR, M. (Ed.). Silicon Ciochemistry, Ciba Fundation Symposium 121. London : John Wiley \& Sons, 1986. p.160-179.

FIMREITE, N., HANSEN, O.O., PETTERSEN, H.C. Aluminium concentrations in selected foods prepared in aluminium cookware, and its implications for human health. Bulletin of Environmental Contamination and Toxicology, New York, v.58, n.1, p.1-7, 1997.

FLINT, N.G., PACKIRISAMY, S. Purity of food cooked in stainless steel utensils. Food Additives and Contaminants, London, v.14, n.2, p.115-126, 1997.

GIBSON, R.S., DONOVAN, U.M., HEATH, A-L.M. Dietary strategies to improve the iron and zinc nutriture of young women following a vegetarian diet. Plant Foods for Human Nutrition, Dordrecht, v.51, n.1, p.1-16, 1997.

GRAMICCIONI, L., INGRAO, G., MILANA, M.R., SANTARONI, P., TOMASSI, G. Aluminium levels in Italian diets and in selected foods from aluminium utensils. Food Additives and Contaminants, London, v.13, n.7, p.767-774, 1996.

GREGER, J.L., GOETZ, W., SULLIVAN, D. Aluminum levels in foods cooked and stored in aluminum pans, trays and foil. Journal of Food Protection, Ames, v.48, n.9, p.772-777, 1985.

KAKADE, V., AGTE, V. Effect of using iron utensils vis-a-vis teflon-coated non stick wares on ionisable iron content of tradicional vegetarian foods. Journal of Food Science and Technology, Bangalore, v.34, n.5, p.427-430, 1997.

KOLLIPARA, U.K., BRITTIN, H. C. Increased iron content of some Indian foods due to cookware. Journal of the American Dietetic Association, Chicago, v.96, n.5, p.508-511, 1996.

KULIGOWSKI, J., HALPERIN, K.M. Stainless steel cookware as a significant source of nickel, chromium, and iron. Archives of Environmental Contamination and Toxicology, New York, v.23, n.2, p.211-215, 1992.

KUMAR, R., SRIVASTAVA, P.K., SRIVASTAVA, S.P. Leaching of heavy metals $(\mathrm{Cr}$, Fe and $\mathrm{Ni}$ ) from stainless steel utensils in food simulants and food materials. Bulletin of Environmental Contamination and Toxicology, New York, v.53, n.2, p.259266, 1994.

LIONE, A. The mobilization of aluminium from cookware. Nutrition Reviews, Washington DC, v.42, n.1, p.31, 1984.

LIONE A., ALLEN, P.W., SMITH, J.C. Aluminium coffee percolators as a source of dietary aluminium. Food Chemical and Toxicology, Oxford, v.22, n.3, p.265-268, 1984.

LIUKKONEN-LILJA, H., PIEPPONE, S. Leaching of aluminium from dishes and packages. Food Additives and Contaminants, London, v.9, n.3, p.213-223, 1992.

LUCKEY, T.D., VENUGOPAL, B. Metal toxity in mammals: physiologic and chemical basis for metal toxity. New York : Plenum Press, 1977. v.1.
MARTINEZ, F.E., VANNUCCHI, H. Bioavailability of iron added to the diet by cooking food in an iron pot. Nutrition Research, Elmsford, v.6, n.4, p.421-428, 1986.

MISTRY, A.N., BRITTIN, H.C., STOCKER, B.J. Availability of iron from food cooked in an iron utensil determined by an in vitro method. Journal of Food Science, Chicago, v.53, n.5, p.1546-1548, 1988.

MONSEN, E. R., HALLBERG, L., LAYRISSE, M., HEGSTED, D.M., COOK, J.D., MERTZ, W., FINCH, C.A. Estimation of available dietary iron. American Journal of Clinical Nutrition, Bethesda, v.31, n.1, p.134-141, 1978.

MORRIS, E.R. Iron. In: MERTZ, W. (Ed.). Trace elements in human and animal nutrition. 5.ed. San Diego : Academic Press, 1986. v.1: p.79-142.

NATIONAL RESEARCH COUNCIL (USA). Recommended Dietary Allowances. 10.ed. Washington DC : National Academy Press, 1989. 284p.

NIELSEN, F.H. Nickel. In: MERTZ, W. (Ed.), Trace elements in human and animal nutrition. 5.ed. San Diego : Academic Press, 1986. v.1: p.245-273.

NIELSEN, F.H. Other trace elements. In: ZIEGLER, E.E., FILER Jr, L.J. (Ed.). Present knowledge in nutrition. 7.ed. Washington DC: ILSI Press, 1996. p.353-377.

ONIWANWA, P.C., IKADEH, G.C., NWEZE, S.E. Aluminium contents of some raw and processed Nigerian foods. Food Chemistry, Barking, v.58, n.4, p.351-353, 1997.

PARK, J., BRITTIN, H.C. Increase iron content of food due to stainless steel cookware. Journal of the American Dietetic Association, Chicago, v.97, n.6, p.659-661, 1997.

PENNINGTON, J.A.T. Aluminium content of foods and diets. Food Additives and Contaminants, London, v.5, n.2, p.161-232, 1987.

ROBERTS, N.S., CLOUGH, A., BELLIA, J.P., KIM, J.Y. Increased absortion of aluminium from a normal dietary intake in dementia. Journal of Inorganinc Biochemistry, New York, v.69, n.3, p.171-176, 1998.

ROCHOW, E.G. Silicon and silicones: about stone-age tools, antique pottery, modern ceramics, computers, space, materials and how they all got that way. Berlim : Spring-Verlog, 1987. p.180.

SMART, G.A., SHERLOCK, J.C. Nickel in foods and the diet. Food Additives and Contaminants, London, v.4, n.1, p.61-71, 1987.

WORLD HEALTH ORGANIZATION. Evaluation of certain food additives and contaminants. Geneva, 1989. p.26-27. (Thirty-third Report of the Joint FAO/WHO Expert Committee on Food Additives; Thechnical Report Series, 776).

YIP, R., DALLMAN, P.R. Iron. In: ZIEGLER, E.E., FILER Jr, L.J. (Ed.). Present knowledge in nutrition. 7.ed. Washington DC : ILSI Press, 1996. p.277-292.

ZHOU, Y D., BRITTIN, H.C. Increased iron content of some Chinese foods due to cooking in steel woks. Journal of the American Dietetic Association, Chicago, v.94, n.10, p.1153-1156, 1994.

Recebido para publicação em 15 de abril e aceito em 8 de novembro de 1999. 